\title{
Correlation of Severity of Coronary Artery Disease with Urine Microalbumin in Indian subjects using Gensini score
}

\author{
Kiran $\mathrm{VH}^{1^{*}}$, Mahadevaswamy $\mathbf{B C}^{2}$ and Padmanabha kamath ${ }^{3}$ \\ ${ }^{1}$ Junior resident Department of Internal Medicine KMC Mangalore , ${ }^{2}$ Junior resident Department of Internal Medicine \\ KMC Mangalore , ${ }^{3}$ Associate professor Department of Cardiology KMC Mangalore, India.
}

Address for correspondence: Dr Kiran VH, Email: vajrabahu2886@gmail.com

\begin{abstract}
Background: Microalbuminuria is one of the simple and independent risk factor for Coronary artery disease. The study was aimed to study the severity of Coronary artery disease with degree of Microalbuminuria using Gensini scoring. Methodology: Our study consisted of 233 subjects admitted for coronary angiography .All subjects were asked detailed medical history mainly concentrating on important risk factors like Diabetes, Hypertension and physical examination was thoroughly carried out; detection of urine Microalbumin and Coronary angiography was carried on. Gensini scoring was used to assess the severity of CAD. Results: Out of 233 subjects which were studied, 140 were diabetics $(60.1 \%) .95 \%$ of Diabetics had abnormal Gensini score, which is statistically significant ( $\mathrm{p}=0.004<0.01), 84 \%$ of Non diabetic subjects had abnormal Gensini score (suggests CAD), with odds ratio 3.6 (CI 1.4 to 9.3). Diabetics had a mean age of 60years and Non Diabetics is 58years in our study. There was good correlation between Microalbuminuria and Gensini score with $\mathrm{r}=$ $+0.510(\mathrm{p}=0.0001)$ and also good correlation between Diabetes duration and Gensini score with $\mathrm{r}=+0.626(\mathrm{p}=0.0001)$. Conclusion: Severity of CAD as assessed by Gensini score was higher in patients with higher microalbuminuria.
\end{abstract}

\section{Introduction}

Although mortality from Coronary Artery Disease (CAD) has declined since the late 1960 and 1970's in most industrialised countries, $\mathrm{CAD}$ is still the leading cause of death [1]. To reduce the burden of cardiovascular disease (CVD), management strategies are increasingly focussing on preventive measures following early detection of markers of atherosclerosis. This article focuses on Microalbuminuria, which is gaining recognition as a simple marker of an atherogenic mileau. Microalbuminuria is a marker of endothelial dysfunction and vascular damage which could be a predictor for coronary artery atherosclerosis $[2,3]$ and early mortality in patients with DM type 2, independent of renal function [4]. Microalbuminuria seems to correlate with various cardiac abnormalities and disease including left ventricular (LV) dysfunction and hypertrophy, electrocardiographic abnormalities, and Ischemic heart disease IHD [5]. Prospective studies confirm that Microalbuminuria is predictive, independently of classical risk factor of cardiovascular diseases and all causes of mortality within groups of

Manuscript received: $8^{\text {th }}$ June 2015

Reviewed: $14^{\text {th }}$ June 2015

Author Corrected: $24^{\text {th }}$ June 2015

Accepted for Publication: $11^{\text {th }}$ July 2015 patients with Diabetes or Hypertension and in the general population. The study was aimed at correlating the severity of CAD with urine microalbumin.

Subjects and Methods: The objectives of the study was explained to the subjects in their preferred language and they were approached individually also. Those subjects who were willing to participate in study only were included and they were well informed regarding the study and a written consent was taken from them. From the Institutional Ethics Committee of KMC (Kasturba Medical College), Mangalore (affiliated to Manipal University), India ethical (ethics committee) approval was taken prior to the commencement of study.

The study which was conducted was a cross-sectional study and it was carried out between December 2011 and December 2012, 233 subjects admitted to the department of cardiology, KMC Mangalore, for elective coronary angiography were enrolled in the study. A semi-structured proforma, was used to collect information regarding study variables like age, sex, presenting complaints, family and past history of angina or ischemic heart disease, duration of Diabetes, duration 
of HTN (hypertension), and subjects were divided into Diabetic \& Non-Diabetics. KMC, Managlore was the place chosen for recruitment of all subjects. Urine Microalbumin was done in KMC hospital lab, Mangalore.
Urine spot sample was sent to NABL accredited K.M.C. Hospital lab, where quantitative estimation of urine albumin was done by an auto analyser.

On the basis of urine albumin excretion, patients were graded as: 0 - $20 \mathrm{mg} / \mathrm{L}$ : Normal and >20mg/L: Microalbuminuria (abnormal).

Coronary Angiogram: Coronary angiogram was performed in a well equipped catheterization lab by a well trained Cardiologist and all images were recorded digitally in a computer. Seldenger's technique was used to perform coronary angiogram. Gensini scoring system was used to assess the severity of coronary artery disease [6].

\begin{tabular}{|l|l|}
\hline Gensini score & Degree of narrowing of lumen of coronary artery \\
\hline Score 1 & $1-25 \%$ \\
\hline Score 2 & $26-50 \%$ \\
\hline Score 4 & $51-75 \%$ \\
\hline Score 8 & $76-90 \%$ \\
\hline Score 16 & $91-99 \%$ \\
\hline Score 32 & Completely occluded artery \\
\hline
\end{tabular}

Gensini score grades the lumen of the coronary artery narrowing and scores it with numerical values with the above mentioned method. The above score is then multiplied by a factor that represents the importance of the lesion's location in the coronary artery system. For the location scores, as below:

\begin{tabular}{|l|l|}
\hline 5 POINTS & LEFT MAIN Coronary artery lesion \\
\hline 2.5 POINTS & Proximal LAD or LCX \\
\hline 1.5 POINTS & Mid segment LAD and LCX \\
\hline 1 POINT & $\begin{array}{l}\text { Distal segment of LAD and LCX, } 1^{\text {ST }} \text { Diagonal branch, First obtuse marginal branch, } \\
\text { RCA, Posterior descending artery and Intermediate artery }\end{array}$ \\
\hline 0.5 POINT & $2^{\mathrm{ND}}$ Diagonal AND $2^{\mathrm{ND}}$ Obtuse marginal branches \\
\hline
\end{tabular}

Statistical methods: Using Student ' $t$ ' test numerical variables were compared between the study groups for independent samples. For comparing categorical data, Chi square (x2) test was performed. Correlation between various variables was done using Karl Pearson correlation. p values less than 0.05 was considered statistically significant

\section{Results}

233 subjects took part in the study, 58 years was the mean age of the subjects with nearly $2 / 3^{\text {rd }}$ of them were between 50 to 70 years, 168 male and 65 female were in the study. 140 were Diabetics out of 233 subjects.

And 118 (50.6\%) subjects were Hypertensive's, family history of Diabetes was present in 177 (76\%). 53.83 was the average Gensini score of our studied population. Gensini score of Zero (Normal Gensini score means no coronary artery disease), was found in around 21 subjects

105subjects (approximately 99\%) had abnormal Gensini score with urine Microalbumin > 20 (suggests CAD) and 106 subjects (approximately 83\%) had abnormal Gensini score with urine Microalbumin<20, which is shown in table 1 . Since the odds ratio is 21 (confidence interval of 2.748 to 157.485 ), there is a strong probability of developing CAD in subjects with high urine Microalbumin levels and the above association is statistically significant $(\mathrm{p}=0.000)$.

We observed in our study that Urine Microalbumin had a Karl Pearson Coefficient Of, $\mathrm{r}=+0.510$, which has strong positive correlation with Gensini score. DM duration had a $r$ value of $r=+0.626$ indicating strong positive correlation with Gensini score. 
Table 1: Comparison of Urine Microalbumin with Gensini score

\begin{tabular}{|l|l|l|l|}
\hline \multirow{2}{*}{$\begin{array}{l}\text { Urine } \\
\text { Microalbumin(microgram/min) }\end{array}$} & \multicolumn{2}{|l|}{ Gensini score No. of subjects(percentage) } & \multirow{2}{*}{ TOTAL } \\
\cline { 2 - 3 } & Abnormal & Normal & \\
\hline$>20$ & $105(99 \%)$ & $1(1 \%)$ & 106 \\
\hline$<20$ & $106(83 \%)$ & $21(17 \%)$ & 127 \\
\hline Total & $211(95 \%)$ & $12(5 \%)$ & $233(100 \%)$ \\
\hline
\end{tabular}

Age $(\mathrm{r}=+0.161)$ and HTN duration $(\mathrm{r}=+0.161)$ have positive correlation with Gensini score.

The correlation of urine Microalbumin with Gensini score is statistically significant so as Age and Diabetes duration.

Gensini score increases with increasing urine Microalbumin levels and DM duration that means Urine Microalbumin and Diabetes duration is directly proportional to severity of CAD and the association between them is strong.

\section{Discussion}

Numerous prospective studies were earlier showed Microalbuminuria as an independent and simple predictor of Coronary artery disease. In a prospective study that involved individuals who were aged 50 to $75 y$ rs, Microalbuminuria was associated with an increased risk for cardiovascular death after adjustment for other risk factors [7]. In present study the degree of Microalbuminuria was accompanied with higher Gensini score which was stastically significant $(\mathrm{P}<$ 0.001). Study of Deveci et al [8] Who found a positive correlation between Microalbuminuria and extent of CAD both in Diabetic and NonDiabetic subjects among 402 subjects he studied and concluded that Microalbuminuria is an independent predictor for the presence $(\mathrm{P}<.001)$ and severity of CAD $(\mathrm{P}<.001, \beta=$ .563). Also our result matches with the study by Sukhija et al [9] who concluded that Microalbuminuria is a independent predictor of severity of CAD both in Diabetic and Non diabetic subjects. The prognostic significance of Microalbuminuria for early mortality after acute myocardial infarction in clinic based patients has been demonstrated [10]. Investigators in the HOPE study made a similar observation in the general population [11]. This above findings clearly states that Microalbuminuria is a predictor and prognostic marker for CAD which matches with our study. The presence of Microalbuminuria also seems to predict all cause mortality in the general population $[12,13,14,15]$ this was initially shown in the prevention of renal and vascular end stage disease (PREVEND) study [12]. The study published by Defilippis et al [16]in 2010 who conducted the MESA study (multi ethnic study of atherosclerosis) also matches with our study. There was a positive correlation between severity of CAD and Microalbuminuria as shown by Guo Lixin et al which matches with our study [17].

\section{Conclusion}

Severity of CAD as assessed by Gensini score was higher in patients with higher Microalbuminuria. Microalbuminuria is an important predictor of coronary artery disease. We can consider it as a cheap and easily available tool to asses cardiac morbidity. This become more important in resource limited countries like India.

\section{Funding: Nil}

Conflict of interest: Nil

Permission from Institutional Research Board (IRB): Yes

\section{References}

1. Rayner M, Petersen S. European cardiovascular disease statistics. British Heart Foundation health promotion research group. Oxford, United Kingdom: department of public health, university of oxford, 2000.

2. Stehouwer CD, Henry RM, Dekker JM, Nijpels G, Heine RJ, Bouter LM. Microalbuminuria is associated with impaired brachial artery, flow-mediated vasodilatation in elderly individuals without and with diabetes: Further evidence for a link between microalbuminuria and endothelial dysfunction -The Hoorn Study. Kidney Int Suppl 2004 Nov;( 92):S42-4.

3. Quyyumi AA. Prognostic value of endothelial function. Am J Cardiol. 2003 Jun 19;91(12A):19H$24 \mathrm{H}$.

4. Adler AI, Boyko EJ, Ahroni JH, Smith DG. Lower extremity amputation in diabetes. The independent effects of peripheral vascular disease sensory neuropathy and foot ulcers. Diabetes care.1999Jul;22(7):1029-35. 
5. Karalliedde J, Viberti G. Microalbuminuria and cardiovascular risk. Am J Hypertens. 2004 Oct;17(10):986-93.

6. Gensini GG. A more meaningful scoring system for determining the severity of coronary heart disease. Am J Cardiol. 1983 Feb;51(3):606.

7. Jager A, Kostense PJ, Ruhe HG, Heine RJ, Nijpels G, Dekker JM, et al. Microalbuminuria and peripheral arterial disease are independent predictors of cardiovascular and all- cause mortality especially among hypertensive subjects: five year follow up of the Hoorn study. Arterioscler Thromb Vasc Biol. 1999 Mar;19(3):617-24.

8. Deveci OS, Kabakci G, Tulumen E, Okutucu S, Aksoy $\mathrm{H}$, et al. The relationship between micoalbuminuria and the presence and extent of coronary atherosclerosis. Angiology. 2010 Feb;61(2):184-91.

9. Sukhija R, Aronow WS, Kakar P, Garza L, Sachdeva R, Sinha A, Mehta JL. Relation of microalbuminuria and coronary artery disease in patients with and without diabetes mellitus. Am J Cardiol. 2006 Aug 1;98(3):27981. Epub 2006 Jun 6.

10. Berton G, Cordiano r, Palmieri R, Cucchini F, De Toni R, Palatine P . Microalbuminuria during acute myocardial infarction : a strong predictor for 1-year mortality. Eur Heart J. 2001 Aug;22(16):1466-75.

11. Gerstein HC, Mann JF, Yi Q, et al. Albuminuria and risk of cardiovasccular events, death, and and heart failure in diabetic and nondiabetic individuals. JAMA. 2001 Jul 25;286(4):421-6..
12. Brantsma AH, Bakker SJ, Hillege HL, De Zeeuw D, De jong PE, Gansevoort RT. Urinary albumin excretion and its relation with $\mathrm{C}$ - reactive protein and the metabolic syndrome in the prediction of type 2 . Diabetes Care. 2005 Oct;28(10):2525-30.

13. Romundstad S, Holmen J, Kvenild K, Hallan H, Ellekjaer H. Microalbuminuria and all cause mortality in 2089 apparently healthy individuals a 4.4 year follow up study.the Nord-Trondelag Health Study (HUNT), norway. Am J Kidney Dis. 2003 Sep;42(3):466-73.

14. Yuyun MF, Khaw KT, Luben $\mathrm{R}$ et al. Microalbuminuria independently predicts all cause and cardiovascular mortality in a British population: The European Prospective Investigation into Cancer in Norfolk (EPIC Norfolk) population study. Int $\mathbf{J}$ Epidemiol. 2004 Feb;33(1):189-98.

15. Klausen K, Borch-Johnsen K, Feldt-Rasmussen B, Jensen G, Clausen P, Scharling H, Appleyard M, Jensen JS. Very low levels of microalbuminuria are associated with increased risk of coronary heart disease and death independently of renal function, hypertension, and diabetes. Circulation. 2004 Jul 6;110(1):32-5..

16. DeFilippis AP, Kramer HJ, Katz R, Wong ND, Bertoni AG, et al. Association between coronary artery calcification progression and microalbuminuria: the MESA study. JACC Cardiovasc Imaging. 2010 Jun;3(6):595-604.

17. Guo LX, Ma J, Cheng Y, Zhang LN, Li M. Urinary albumin excretion rate is correlated with severity of coronary artery disease in elderly type 2 diabetic patients. Chin Med J(Engl) 2012 Dec;125(23):4181-4.

\section{How to cite this article?}

Kiran VH, Mahadevaswamy BC, Padmanabha kamath. Correlation of Severity of Coronary Artery Disease with Urine Microalbumin in Indian subjects using Gensini score. Int $J$ Med Res Rev 2015;3(6):579-582. doi: 10.17511/ijmrr.2015.i6.109. 